\title{
Learning Organization of Industrial Factories in Amata Nakorn Industrial Estate, Chonburi Province. Thailand
}

\author{
Asst. Prof. Dr. Pongsatean Luengalongkot \\ Faculty Member, Graduate School of Public Administration, Burapha University. \\ Email: pongsate@hotmail.com
}

\begin{abstract}
The purposes of this study "Learning Organization of Industrial Factories in Amata Nakorn Industrial Estate, Chonburi Province. Thailand" were, first to study the level of learning organization at industrial factories in Amata Nakorn Industrial Estate. And second to compare the differences of the learning organization at industrial factories in Amata Nakorn Industrial Estate separate by sex, age, education and experience. The sample group used for this study were 190 personnel managers calculated by using Taro Yamane formular. A simple random sampling was applied to get the representatives and a questionnaire was used as the research instrument. To describe the general characteristics of the sample group, descriptive statistic, frequency and percentage were used. To describe the level of leaning organization of the industrial factories, mean and standard deviation were used, In addition to test the hypothesis by analyzing the data to compare between dependent and independent variables, Independent sample t-test and One-way ANOVA were used. The significant difference was set at 0.05 . The results revealed that in the overall picture, it was found that the sample group rated the level of learning organization at the high level. And in each aspect: Personal Mastery, Team Learning, Systematic Thinking, Mental Model, and Shared Vision were all rated at a high level. The research found that, the personnel managers who have different sexes, ages and educations have not different opinion toward learning organization. The personnel managers who have different experiences have different opinion toward learning organization.
\end{abstract}

Keywords: Learning Organization

\section{Introduction}

Thai industry is continuously expanding, The number of industrial workplaces in Thailand increase rapidly and needs for more workers follow. To be a consideration working in the industrial sector is an interesting way of life. And the more workplaces increase, the more labors are needed. So, the growth of industry helps to generate advancement and distribute jobs to domestic labors. However, the global situation is changing rapidly and in many ways such as knowledge, technology and consumer requirements. As a result, the organizations have to encourage and develop their personnel to be ready to work in changing situations. Learning organization is crucial because the only the well adapted organization can be survival. The adjustment due to competition has changed the simple working life of workers to a more challenging ways of life in order to cope with the following problems. The first problem relates to limited world resources which needs good resource management approaches. The organization should pay much attention to develop knowledge for potential personnel so as to be ready to manage resources for the highest benefits and to be sustainable. The second problem is globalization has brought about the idea of shared benefits, values and tastes especially, the continuing expansion of industrial business in the national economy. The world economy has created the level of a world organization and assumes that the globe is their markets. Every business activity will be joined to reinforce, to increase capability and to compete at the world level. Moreover, there is a transfer of production lines to other countries because of cheaper labors. As a result, there is a need for high quality manpower to develop structure and organization to become a world class organization. Thus, there is a need for quality workers to develop the organization. (Verawut Makasiranon, 2006) The last problem is technology since it has now become a part of the working process. The internet and the intranet systems have shortened the communication information process. Technology requires personnel or staff to become self-directed learning people and be ready to deal with technology in order to work with quality in the future. As earlier mentioned, it shows that every industrial factory attempts to create quality and effectiveness of the organization in the overall picture. They 
believe that learning organization is crucial and the heart of a learning organization depends on discipline and includes 5 characteristics. Senge describes the learning organization as "the place where persons try to expand their capabilities to create work needed in the future". The discipline consists of Personal Mastery, Mental Model, Shared Vision, Team Learning, and Systematic Thinking. (Senge, 1990)

Amata Nakorn Industrial estate established in the Eastern Region of Thailand located at Muang District, Pantong District. The estate has 15,000 Rai and 349 factories. (Amata Nakorn Industrial Estate, 2006) The investment costs more than 50,000 million baht and there are 61,484 workers. Most of the factories operate on electrical machines, electrical equipments and electronic devices. Amata Nakorn Industrial Estate has a policy to encourage learning in all companies operating on its site, at the same time, the company on its site would also wants help their personnel to be able to work effectively. There is a need for high quality manpower to develop structure and organization to become a world class organization. According to the statement mentioned above the researcher would like to

Independent Variables seek the answer about the level in the learning organization of the factories at the Amata Nakorn Industrial Estate? The results would benefit the factory and personnel management to develop their own learning organizations in the future.

\section{Objectives of the Research}

1) To study the level of learning organization of industrial factories in Amata Nakorn Industrial Estate.

2) To compare the differences of learning organization of industrial factories in Amata Nakorn Industrial Estate separate by sex, age, education and working experience.

\section{Conceptual Framwork}

The conceptual framework consisted of these main ideas to learning organization in the industrial factories in Amata Nakorn Industrial Estate Chonburi, Thailand. The learning organization theory come from Peter Senge, 1990 consisted of Personal Mastery, Mental Model, Shared Vision, Team Learning and Systematic Thinking.

\section{Dependent Variables}

\section{Figure 1 Conceptual Framework}

\section{The Research Hypothesis}

The research hypothesis consisted of the following statements:

1) The personnel managers who have different sexes have different opinion toward learning organization.

2) The personnel managers who have different ages have different opinion toward learning organization.

3) The personnel managers who have different educations have different opinion toward learning organization.

4) The personnel managers who have different experiences have different opinion toward learning organization.

\section{Expected Benefit of this Study}

1) It will be able to exactly know the level of learning organization at industrial factories in Amata Nakorn Industrial Estate.

2) The result of this research will make the relevant factory comprehend the different of opinion toward learning organization at industrial factories in Amata Nakorn Industrial Estate. 


\section{Research Methodology}

\subsection{Population and Sample}

The population of this study consisted of 349 personnel managers from the factories at the Amata Nakorn Industrial Estate. The sample group was 190 personnel managers calculated by using Taro Yamane formular. A simple random sampling was applied to get the sample size. (Chaleamphol Srihong,1999 p. 9)

\subsection{Research Instrument}

The researcher constructed a questionnaire to collect the data and the reliability of the questionnaire was .983 . There were 2 parts in the questionnaire:

Part 1 It dealt with the basic information of the respondent such as sex, age, education and working experience. This part composted of 4 questions.

Part 2 It dealt with the level of learning organization of the industrial factories which consisted of five disciplines, Personal Mastery, Mental Model, Shared Vision, Team learning, and Systematic thinking. There were 25 items in this part.

\section{Data Analysis}

The analysis of data was managed in the following manners.

1) To describe the general characteristics of the sample group, descriptive statistic, frequency and percentage were used.

2) To describe the level of leaning organization of the industrial factories, mean and standard deviation were used.

3) To test the hypothesis by analyzing the data to compare between dependent and independent variables, Independent sample t-test and One-way ANOVA were used. The significant difference was set at 0.05 .

\section{Research Result}

The level of opinion toward learning organization of industrial factories at the Amata Nakorn Industrial Estate.

In the overall picture, it was found that the sample group rated the level of learning organization at the high level. And in each aspect, Personal Mastery, Team Learning, Systematic Thinking, Mental Model, and Shared Vision were all rated at a high level. The sample group rated the level of learning organization In the overall picture at the high level due to every industrial factory attempts to create quality and effectiveness of their organization. They believe that the heart of a learning organization depends on discipline along with other 5 characteristics. Senge describes the learning organization as "the place where persons try to expand their capabilities to create work needed in the future”. The discipline consists of Personal Mastery, Mental Model, Shared Vision, Team Learning and Systematic Thinking (Senge, 1990). The result was in accordance with Luechai Chanpoe (2003) and Boonthum Boranmul (2005). The first one studied with Learning Organization Model in the Catholic Vocational School of Thailand and the other studied the factors influencing learning organizations at a schools in the municipal of Khonkan , Khonkan province. They found that the learning organizations were rated at a high level. Moreover, Poethiya Kumphew (2005) also found that the level of learning organization in schools in Nongkai Education Region was rated at a high level. The learning organization was rated at a high level and the researcher assumes that every factory believe that learning organization is crucial bring about every factory needs to improve their organization to be the learning organization in order to get ready for competition and survival. Furthermore, if company develop and transform to learning organizations it will produce high quality product.

The differences of opinion toward the learning organization at industrial factories in Amata Nakorn Industrial Estate separate by sex, ages, educations and experiences.

The research found that, the personnel managers who have different sexes, ages and educations have not difference of opinion toward learning organization.

On the contrary the personnel managers who have different working experiences have different of opinion toward learning organization. The researcher assumes that the personnel managers who have a lot of experiences have perceived and acknowledge in benefit of learning organization. They know if company develop and transform to learning organizations, it will be a world class company and manufacturing and can be survived in the world of competition. (Verawut Makasiranon, 2006). The personnel managers who have a lot of experiences are high quality employees to develop structure and organization to become a learning organization and a world class manufacturing. 


\section{Recommendations}

\subsection{Policy Recommendations}

9.1.1 The research found that as far as the opinion toward the level of learning organization, shared vision earned the lowest average. Thus, each factory should formulate and implement a policy to encourage personnel to develop visions, goals, objectives and strategy for more working effectiveness.

9.1.2 The results also showed that personal mastery gained the highest average. The factory should promote and support training policies to encourage personnel or stimulate them to continue self development.

\subsection{Recommendations for Practice}

9.2.1 The factory should have staff meetings to develop the companies' visions.

9.2.2 The factory should provide a library to encourage employee self-learning.

\subsection{Recommendations for Further Study}

There should be a study conducted on the level of learning organization in other industrial estates.

\section{References}

[1] Amata Nakorn Industrial Estate. (2006). Retrieved December 22, 2006, from http://www.ieat.go.th.

[2] Boontam Boranmul. (2005). The factor influencing for learning organization of school in the control of municipal Khonkan ,Khonkan province. Master Degree thesis, Education Management, Khonkan University.

[3] Chaleamphol Srihong.(1999). Research Methodology. n.p.

[4] Luechai Chanpoe. (2003). Learning Organization Model in Catholic Vocational School of Thailand. Doctoral Degree thesis, Vocational Education, King Mongkut's Institute of Technology Ladkrabang.

[5] Poethiya Kumphew. (2005). The factor influencing for learning organization of school in A.Mueng in the control of Nongkai Education Region1. Master Degree thesis, Education Management, Khonkan University.

[6] Senge. Peter M. (1990). The fifth discipline : The art and Practice of the learning organization. New York: Double day currency.

[7] Veravut Makasiranon. (2006). Development learning organization. Bangkok: Tramkamol Printing. 